\title{
MEDICINE AND THE LAW Vaginal deliveries - is there a need for documented consent?
}

\author{
A Dhai, J Gardner, Y Guidozzi, G Howarth, M Vorster
}

A pregnant woman nearing delivery, with an uncomplicated pregnancy and no immediate indication for caesarean section (CS), can either deliver vaginally or by CS. Historically CS has been viewed as more dangerous than vaginal delivery. However, CSs are far safer today and the complications of unmonitored labour are increasing, especially in the public sector.

Delivery should be discussed during the antenatal period. The decision to have a CS is usually followed by signing an authorisation form - incorrectly referred to as the consent form. Women who decide to deliver vaginally are not asked to sign a similar form, possibly because consent is procedure specific and a vaginal delivery is not seen as a procedure. However, natural birth, a normal physiological process, and modern medical vaginal childbirth are not synonymous and each intervention in the latter requires consent, albeit often tacit.

The merits of antenatal care and monitored childbirth are obvious. However, it is not clear to most people that when a woman seeks medical attention and is admitted into an antenatal programme for her pregnancy and subsequent childbirth (including a 'normal' vaginal delivery), there is a transition to medicalised care. Hence the ethical and legal tenets must apply to management in this context. Therefore, does the modern medical vaginal birth process itself require an authorisation form? This is because the process includes medical interventions and unique risks, and there is a clear alternative. When well informed the woman has probably passed the threshold for consent from an ethical point of view, but is there an additional legal threshold that must be crossed, given the increasing tendency to litigation?

While presenting current scientific opinions on the risks and benefits associated with vaginal and abdominal delivery, we do not argue for either mode of delivery. We recognise women's right to choice in respect of mode of delivery. We argue that even when a normal vaginal delivery is anticipated, the practitioner is obliged to discuss the alternative of CS with the woman. We argue that the context and environment of the delivery ward are important components of the communication. These are informed by the

A Dhai is Director of the Steve Biko Centre for Bioethics and Head of the Bioethics Discipline of the Faculty of Health Sciences, University of the Witwatersrand, Johannesburg.

$J$ Gardner is a lecturer and postgraduate academic co-ordinator and Y Guidozzi a lecturer in the Steve Biko Centre for Bioethics.

$G$ Howarth is full-time medico-legal advisor and Head of Medical Services - Africa, Medical Protection Society, UK.

$M$ Vorster is an honorary lecturer in the Steve Biko Centre for Bioethics and Vice-Dean Faculty of Health Sciences, University of the Witwatersrand. doctrine of informed consent, which we examine from the legal perspective. We aim to stimulate discussion and debate on the current and future status of vaginal deliveries.

\section{Vaginal delivery or caesarean section - the facts}

Despite being more costly and associated with maternal and neonatal complications, morbidity and mortality more often than vaginal delivery, ${ }^{1-4} \mathrm{CS}$ is an increasingly common procedure in the public and private sectors in South Africa. ${ }^{5}$

South Africa's CS rate is much higher than the ideal rate of 10 $15 \%$ in low-risk obstetric populations recommended by the World Health Organization in $1985 .{ }^{6}$ According to the Health Systems Trust the public sector rate was about $17 \%$ in 2005 , and rates of about $30 \%$ were reported by regional and tertiary public hospitals in Durban. ${ }^{5}$ High CS rates have been reported in the private health sector in South Africa, ${ }^{7}$ with a rate of $60.4 \%$ in Durban. ${ }^{5}$ Comparing CS deliveries in the private sector with teaching and public hospitals in Gauteng, a study between 1998 and 2000 found, on average, a CS rate of 57\% (11 572 CSs in 20151 deliveries) at six private hospitals compared with $28 \%$ and $19 \%$ in one teaching hospital and 20 public hospitals, respectively. ${ }^{8}$

\section{Reasons for high CS rates}

Several factors contribute to the high CS rates. Beyond HIV status, planned CS at maternal request contributes significantly. ${ }^{5}$ CSs requested by women are commonly done electively. Reasons for requesting CS include fears of labour and delivery (tocophobia), convenience, control, and the preservation of pelvic floor function. Advantages of elective CS include controlling the specific date and time of childbirth, maximising maternity leave, and anecdotal evidence that women think a CS is safer for the mother and/or the baby, which is not necessarily true.

Surveys indicate that fear of litigation and the desire for safer deliveries are the primary reasons for conducting non-essential CSs. ${ }^{9,10}$ The threat of malpractice is real in health care practice. In general, undertaking any procedure without evidence-based indications and informed consent from the patient constitutes an assault on the patient, for which doctors can be and have been held liable. It is therefore not surprising that some doctors believe that performing a CS reduces the risk of being sued, even if a vaginal birth may be the optimal care.

Despite many factors contributing to high CS rates, internationally there is insufficient evidence for a full evaluation of the benefits and risks of non-medically indicated CS compared with planned vaginal delivery. Expert opinion is that until substantive evidence is available, the mode of delivery should be based on sound ethical principles. ${ }^{11}$ We believe that the mode of delivery should also be based on sound legal principles, which include discussing the option of CS with a woman in whom a normal vaginal delivery is anticipated. Distinct qualitative differences in morbidity between the two modes of delivery must be brought to the patient's attention. Morbidity and mortality are three times higher when CSs are unplanned and performed as emergency procedures. ${ }^{12}$ 


\section{Ethical issues}

Worldwide, the medical profession supports a woman's right to make health care decisions for herself and her unborn child. Doctors are obliged to disclose the risks and benefits of any recommended treatment, test or procedure to their patients, who can then make an informed decision and exercise their right to choose between or refuse available options. When a planned vaginal delivery is decided on, the significant questions are how the doctor should counsel patients who will deliver vaginally, and how much information they should receive. Should the woman receive information in respect of the labour ward, e.g. that due to human resource constraints a midwife may not be available at her bedside throughout the labour? Will tacit consent suffice today, or is there now a need for documented and authorised consent?

Respect for patient autonomy is an ethical and legal imperative and obliges doctors to disclose appropriate information to patients so that they can make an informed decision about their health care. Competent patients may accept or refuse any recommended treatment, and the doctor's role, grounded in beneficence-based obligations, is to identify medically reasonable alternatives, i.e. those reliably expected to result in a greater balance of clinical good over clinical harm for the patient. This has been seen as the first step of the informed consent process. ${ }^{11}$ In subsequent steps the patient reaches a decision about whether to accept or to reject one of these medically reasonable alternatives. ${ }^{13}$ We propose that more than medical information is necessary. Information should include the context of the labour ward environment and whether or not the facilities are able to provide continuous care and monitoring by qualified nursing staff. It follows, therefore, that non-medical risks with the potential for medical complications must be included in the information. We stress, however, that counselling should be nondirective.

The patient's role in the informed consent process involves the exercise of a negative right, i.e. the right not to be interfered with in her making of decisions and her own behaviour. ${ }^{13}$ However, these rights must be considered together with positive rights, which involve claims on the resources of others to achieve one's intentions and goals. Because positive rights involve sacrifice by others, they come with limits; the issue in such situations concerns the scope of such limits. Respect for patient autonomy can justifiably be limited by a doctor's beneficence-based obligations. ${ }^{14-16}$ We believe that the doctor's beneficence-based obligations when informing the woman of the benefits and risks of a planned vaginal delivery include information on labour ward resources.

\section{Informed consent for vaginal deliveries - a summary of South African law}

The doctrine of informed consent and whether a doctor's failure to inform the patient amounts to negligence or assault is legally controversial. ${ }^{17}$ English and Australian legal systems favour consent to medical treatment, viewing it as related to the doctor's duty of care to a patient and classifying its breach as negligence. However, South African law supports the stance that lack of consent amounts to assault (violation of physical integrity) and not medical negligence. Our common law recognises that an unlawful infliction of bodily harm amounts to the offence of injuria. ${ }^{18,19}$ As early as 1908 this included an offence to dignity, privacy, reputation and ultimately bodily integrity, which confirmed the importance of a person's autonomy and right to self-determination in law. The Bill of Rights in the Constitution of South Africa finally cast this in stone. ${ }^{20}$
The Constitution provides that everyone has the right to dignity and bodily integrity. The realisation of these rights is brought about by the National Health Act (NHA), ${ }^{21}$ which provides for these rights to be protected. It states that the patient has a right to have full knowledge' through the health provider informing the patient, in a language she understands, of her health status (except where it is not in the patient's best interests to do so) and the range of diagnostic procedures and treatment options available, including the benefits, risks, costs and consequences associated with them. By bringing in costs, the Act recognises that non-medical information is part of disclosure. This could include the context of the delivery room environment. The South African courts have determined how much information to give a patient about the risks. Patients must be told about all 'material risks' related to a procedure or treatment, i.e. risks to which a reasonable person in the patient's position would attach importance, and that a health practitioner would reasonably be aware would be considered significant by a patient warned about them. ${ }^{22,23}$ This could apply to the environment in the labour ward. Patients must also be informed that they may refuse health services and the implications of such refusal. However, with the advent of the NHA, the Consumer Protection Act No. 68 of 2008, the Patient's Rights Charter ${ }^{24}$ and the HPCSA Guidelines on Informed Consent ${ }^{23}$ stricter criteria are currently employed and we are seeing a shift from the reasonable person to individual patient requirements.

The Consumer Protection Act 68 of 2008, to be promulgated, affirms in s54 (1) (b) that a consumer has the right to the performance of services in a manner and quality that persons are generally entitled to expect, and taking into account any specific conditions agreed between the supplier and consumer before or during the performance of the services. If a doctor does not provide management in a manner and of the quality that a patient would generally be entitled to expect, the patient may therefore require that the doctor remedy the defect or refund that portion of the price paid, depending on the extent of the failure. The court may also declare the provision or notice or the whole agreement to have no force or effect (s52).

A patient therefore has a right to participate in the decisionmaking process. The doctrine of informed consent, a cornerstone of the doctor/patient relationship, could lead to possible litigation if compromised. ${ }^{17}$

Consequently, in light of the NHA, the doctor will only be protected where a patient expressly provides informed consent. To argue that tacit consent was given by conduct will be insufficient. Consent could be written or verbal, but written consent/authorisation for normal vaginal deliveries would be legally prudent although not legally necessary.

Problems arise for both the doctor and patient when a woman presents for the first time in labour and requiring admission, which often happens in the public sector. It may not be said that her presence translates to consent by conduct. In theory she would require a full explanation of what treatment and procedures to expect, and should be given options, but she would probably not be in the right frame of mind to absorb all the information and reach an informed decision. Furthermore, unexpected complications may require additional consent for a surgical intervention or anaesthetic procedure, such as an epidural, which she had not previously been warned about or prepared for. The timing of seeking consent at this stage is problematic. The woman may be distracted or distressed and the opportunity to explain the procedure as required by the NHA is limited, so it may in future be argued that 'informed' consent was not in fact given. In an emergency this would probably be considered legal, but many situations are not strictly emergencies. 
Approaching informed consent as a process of communication ${ }^{25}$ throughout the antenatal period would be ideal for the woman preparing for childbirth and the health care provider. All options could then be discussed timeously, so that the mother-to-be would be prepared for the possibility of having a CS or for the complications of and interventions sometimes required for a vaginal delivery. The health care provider could also explain that not all complications arise at birth because of the birth process, and that some problems present during the antenatal period and are only identified at or even after birth, such as a fetal heart defect.

Asking a woman to sign an informed consent form specifically for a vaginal delivery has advantages. These include the additional time spent by the health care practitioner discussing her and the baby's health status, and explaining the options available to her, the risks and benefits of these options, the costs involved should these be relevant, and the right to refuse any aspect of treatment with which she would not be comfortable. The woman would then also be made aware that although a vaginal delivery may be considered a wholly 'natural process', many situations cannot be predicted but only controlled to the best of the medical personnel's ability should they arise. If the consent form can be signed by the woman before the date of delivery she will have been able to think about what she has been told and the consent process will not have been compromised because of labour pains. The health care practitioner would then also have proof that the information surrounding the process has been communicated as required by law should there be any query later on.

\section{Conclusion}

We have argued that as patient advocates and promoters of overall patient health and welfare, doctors should obtain written consent/ authorisation for a 'normal' vaginal delivery in the antenatal period where indicated. Material to the discussions would be the environment in the labour ward and whether or not continuous oversight of the labour process by qualified nursing staff will be available. We are well aware of issues pertaining to resource constraints, especially in state settings. However, the informed consent process should not differ between private and public health care settings, and women in the public sector should be made aware not only of their rights to choice but also the limitations of these rights consequent to a lack of resources.

The authors thank Professor Franco Guidozzi for his advice and guidance while they were writing this paper.

Snyman L. Is the high caesarean section rate a cause for concern? Obstetetrics and Gynaecology Forum 2002;12(2):8-13.

Hager RM, Daltveit AK, Hofoss D, et al. Complications of cesarean deliveries: rates and risk factors. Am J Obstet Gynecol, 2004;190:428-34.

. Rageth JC, Juzi C, Grossenbacher H. Delivery after previous cesarean: a risk evaluation. Obstet Gynecol 1999; $93: 332-337$

4. Hibbard JC, Ismail MA, Wang Y, et al. Failed vaginal birth after a cesarean section: how risky is it? I. Maternal morbidity. Am J Obstet Gynecol 2001;184:1365-1371.

. Naidoo N, Moodley J. Rising rates of caesarean sections: an audit of caesarean sections in a specialist Naidoo N, Moodley J. Rising rates of caesarean sections: an audit of
private practice. South African Family Practice 2009;51(3):254-258.

private practice. South African Family Practice 2009;51(3):254-258.
World Health Organization. Appropriate technology for birth. Lancet 1985;2:436-467.

6. World Health Organization. Appropriate technology for birth. Lancet 1985;2:436-467.
7. Matshidze KP, Richter LM, Ellison GT, Levin JB, McIntyre JA. Caesarean section rates in South Africa: Matshidze KP, Richter LM, Ellison GT, Levin JB, McIntyre JA. Caesarean section rates
evidence of bias among different 'population groups.' Ethn Health 1998;3(1-2):71-79.

8. Tshibangu KC, De Jongh MA, De Villiers DJ, Du Toit JJ, Shah SMH. Incidence and outcome of caesarean section in the private sector -3 year experience at Pretoria Gynaecological Hospital. S Afr Med J 2002;92(12):956-959.

9. Chalmers B, McIntyre J, Meyer D. South African obstetrician's views on caesarean section. S Afr Med J 1992;82:161-163.

10. Dommisse J. Is your caesarean section necessary? S Afr Med J 1996;86:276.

11. Kalish RB, McCullough LB, Chervenak FA. Patient choice cesarean delivery: ethical issues. Curr Opin Obstet Gynecol 2008;20:116-119.

12. Van Ham MAPC, van Dongen P, Mulder J. Maternal consequences of caesarean section. A retrospective study of intraoperative and post-operative maternal complications of caesarean section during a 10

13. Brett AS, McCullough LB. When patients request specific interventions: Defining the limits of the Brett AS, McCullough LB. When patients request specific
physician's obligation. N Eng J Med 1986;315:1347-1351.

14. Minkoff H, Powderly KR, Chervenak F, McCullough LB. Ethical dimensions of elective primary Minkoff H, Powderly KR, Chervenak F, McCullough
cesarean delivery. Obstet Gynecol 2004;103(2):387-392.

15. Chervenak FA, McCullough LB. An ethically justified algorithm for offering, recommending,
, and performing cesarean delivery and its application in managed care practice. Obstet Gynecol 1996;87:302-305.

6. McCullough LB, Chervenak FA. Ethics in Obstetrics and Gynecology. New York: Oxford University Press, 1994.

17. Carstens P, Pearmain D. Foundational Principles of South African Medical Law. Durban: LexisNexis Butterworths, 2007: 677.

8. Stoffberg v Elliott 1923 CPD 149.

19. Rex v Jack 1908 TS 131.

20. The Constitution of South Africa, Act No. 108 of 1996.

21. National Health Act No. 61 of 2003.

22. Castell v De Greef 1994 (4) SA 408 (C) at 426.

22. Castell v De Greef 1994 (4) SA 408 (C) at 426 . Booklet 9: Seeking Patients Informed Consent: The Ethical Considerations. Pretoria: Health
Professions Council of South Africa. May 2008. Health Professions Council of South Africa Ethics Professions Council of South Africa. May 2008. Health Professions Council of South Africa Ethics
Guideline Booklets. http://www.hpcsa.co.za/downloads/conduct_ethics/rules/generic_ethical_rules (accessed 3 September 2010)

24. Booklet 3: National Patient's Rights Charter. Pretoria: Health Professions Council of South Africa. May 2008. Health Professions Council of South Africa Ethics Guideline Booklets. http://www.hpcsa.co.za/ downloads/conduct_ethics/rules/generic_ethical_rules (accessed 3 September 2010).

25. Bernat JL, Peterson LM. Patient-centered informed consent in surgical practice. Arch Surg 2006;141(1):86-92. 